\title{
DESIGN E ENGENHARIA: UM CASE DE EMPREENDEDORISMO SOCIAL
}

Carlos Alberto Silva de Miranda, Dr.

Faculdade IBMEC/MG - Escola de Engenharia

Cmiranda3@ibmec.edu.br

Artur Caron Mottin, M.Sc.

Universidade do Estado de Minas Gerais

mottindesign@gmail.com

Jéssica Carvalhais Paiva Ferreira

Faculdade IBMEC/MG - Escola de Engenharia

jessicacarvalhaispf@gmail.com

Clara de Melo Trindade

Universidade do Estado de Minas Gerais

claramtrindade@gmail.com

Resumo: O empreendedorismo social surgiu nas últimas décadas como uma forma de identificar e promover mudanças potencialmente transformadoras na sociedade. Um híbrido de intervenção governamental e puro empreendedorismo de negócios, o empreendimento social é capaz de tratar problemas cujo âmbito é estreito demais para instigar o ativismo legislativo ou para atrair capital privado. As competências, nas diferentes abordagens entre os autores que discutem o tema, são geralmente relacionadas não somente à formação, mas também à aptidão nata, à ação e mobilização, aos resultados e aos desenvolvimentos de perspectivas dinâmicas, bem como ao autodesenvolvimento que provém da interação. A experimentação e o aprofundamento frente a problemas sistêmicos, sejam eles de quaisquer graus de dificuldade ou natureza, geram um repertório que prepara os futuros profissionais para encarar qualquer tipo de desafio. Dentro do contexto apresentado, descrevemos neste trabalho os resultados das primeiras ações do Projeto Protosonho, que consiste na produção e doação de próteses humanas de baixo custo em impressora 3D, com o foco em oferecer melhor qualidade de vida para deficientes físicos de baixo poder aquisitivo. O projeto se baseou na disponibilidade de diversos projetos open source, disponibilizados na internet em plataformas virtuais, os quais seriam adequados e teriam seus projetos otimizados através de intervenções de engenharia e design. Ademais, o conhecimento prévio de alguns dos mentores do Projeto, devido à experimentação anterior, foi muito útil para evitar e contornar alguns problemas quanto à impressão e funcionamento mecânico da prótese. Aqui estão descritos os primeiros resultados 
positivos e metodologias projetuais aplicados. Relatamos ainda as etapas de desenvolvimento do trabalho em conjunto, a partir de uma equipe multidisciplinar, o que também enriqueceu o processo e tornou atrativo o contexto de atuação dos agentes, a partir das competências que atuaram se completando, seja na organização, seja na alocação de recursos, seja na execução, propriamente dita, do projeto.

Palavras-chave: Prótese, impressão 3D, FDM, design de produto, empreendedorismo social.

Abstract: Social entrepreneurship has emerged in recent decades as a way to identify and promote potentially transformative changes in society. A hybrid of government intervention and pure entrepreneurship business, social enterprise is able to deal with problems whose scope is too narrow to instigate legislative activism or to attract private capital. The skills, the different approaches among the authors who discuss the topic, are usually related not only training, but also for cream fitness, action and mobilization, results and developments of dynamic perspectives, as well as self-development that comes from interaction. Experimentation and forward deepening the systemic problems, whether any degree of difficulty or nature, generate a repertoire that prepares future professionals to face any kind of challenge. Within the context presented, we describe in this paper the results of the first actions of Protosonho Project, which is the production and donation of low cost human prostheses 3D printer, with the focus on providing better quality of life for disabled people with low purchasing power. The project was based on the availability of several open source projects available on the Internet in virtual platforms, which would be appropriate and would have their designs optimized through engineering interventions and design. In addition, prior knowledge of some of the Project mentors, because the previous trial, was very helpful to avoid and circumvent some problems regarding the printing and mechanical operation of the prosthesis. The first positive results and applied projective methods and described here. We also relate the work stages of development together, from a multidisciplinary team, which also enriched the process and made it attractive to agents of the operating context, from the powers acted to completing either the organization or resources allocation, in the execution of the project.

Keywords: Prosthesis, 3D printing, FDM, product design, social entrepreneurship.

\section{O EMPREENDEDORISMO SOCIAL COMO PONTO DE PARTIDA}

O empreendedorismo social surgiu nas últimas décadas como uma forma de identificar e promover mudanças potencialmente transformadoras na sociedade. Um híbrido de intervenção governamental e puro empreendedorismo de negócios, o empreendimento social é capaz de tratar problemas cujo âmbito é estreito demais para instigar o ativismo legislativo ou para atrair capital privado (MARTIN \& OSBERG, 2015). 
O sucesso desses empreendimentos depende tanto de uma adoção das metas sociais quanto de restrições financeiras rígidas. Tipicamente, o objetivo é beneficiar um grupo específico de pessoas, transformando suas vidas de modo permanente ao alterar um equilíbrio socioeconômico prevalecente que opera em detrimento de seus interesses. Às vezes, como acontece com o empreendedorismo ambiental, o benefício pode se estender a um grupo mais amplo, uma vez que o projeto tiver fornecido prova de conceito. Porém, na maioria das vezes, o alvo do benefício é um segmento da sociedade marginalizado ou em situação de desvantagem econômica que não conta com os meios para transformar seus prospectos sociais ou econômicos.

Para a Ashoka (2016), os empreendedores sociais são indivíduos com soluções inovadoras para os problemas sociais mais urgentes da sociedade. Estes têm perfil ambicioso e persistente, enfrentando as grandes questões sociais e propondo novas ideias de mudança em larga escala, identificando os pontos no sistema que não funcionam, propondo e implementando soluções, além de atuarem, persuadindo a sociedade a mudar os modelos mentais e a quebrar os paradigmas. O que os caracteriza como empreendedores, portanto, é o fato de não relegarem estas necessidades para o setor público ou privado, ao desenvolverem soluções sustentáveis. A Ashoka é uma comunidade mundial que reúne cerca de 3.000 empreendedores sociais líderes e a maior organização global de investimento em ideias inovadoras e nos seus autores. O Brasil tem o maior programa da Ashoka no mundo.

Para Drucker (1987), o empreendedorismo nem sempre requer finalidade de lucro. A partir deste ponto de vista, segundo Silva (2003), poderemos notar que ao decorrer das últimas décadas, as denominadas organizações sem fins lucrativos recorrentemente tem se utilizado das ferramentas gerenciais que fundamentam o empreendedorismo, o que possibilitou o delineamento conceitual desta nova área de conhecimento: o empreendedorismo social.

Segundo Vieira \& Gauthier (2000), os empreendedores sociais são aqueles agentes que criam valores sociais através da inovação e da força de recursos financeiros, independente da sua origem, visando o desenvolvimento social, econômico e comunitário de uma sociedade. Para estes autores, os empreendedores sociais têm visão, criatividade, e determinação, se tornando os pioneiros na inovação de soluções para os problemas sociais mais prementes e não descansam até mudarem todo o modelo mental que torna a resolução destes problemas um paradigma perante a sociedade.

Para David (2004), no empreendedorismo social a economia passa a funcionar a serviço da comunidade. E o foco das atenções do empreendedor social não está no registro de marcas e patentes, nem na sua exploração econômica, mas na divulgação e multiplicação de suas idéias. Para esta autora, esta é a razão do impacto nacional de projetos tais como: soro caseiro, bolsa-escola, médicos de família, universidade solidária e tantos outros.

Para Borchardt Et. Al. (2007), ainda que tenha surgido como uma evolução do conceito de qualificação, há muito a visão de competências individuais deixou de ser apenas o somatório de conhecimentos, habilidades e atitudes. Foram incluídos outros aspectos como a mobilização, o contexto e o resultado. Estes autores também referenciam o trabalho de Bitencourt (2001), que julga que as 
competências, nas diferentes abordagens entre os autores que discutem o tema, são geralmente relacionadas não somente à formação, mas também à aptidão nata, à ação e mobilização, aos resultados e aos desenvolvimentos de perspectivas dinâmicas, bem como ao autodesenvolvimento que provém da interação. A experimentação e o aprofundamento frente a problemas sistêmicos, sejam eles de quaisquer grau de dificuldade ou natureza, geram um repertório que prepara os futuros profissionais para encarar qualquer tipo de desafio.

\section{O PROJETO PROTOSONHO}

Dentro do contexto apresentado, a IBMEC SOCIAL é um dos Programas de Extensão da Faculdade IBMEC de Minas Gerais, que visa fomentar o empreendedorismo social de alto impacto no Brasil. Com o propósito de gerar transformações positivas na sociedade, o Programa tem como objetivo promover e executar iniciativas sustentáveis, no longo prazo, que desenvolvam habilidades gerenciais e empreendedoras em seus membros. Na IES, a IBMEC SOCIAL é considerada uma Liga Universitária, na qual o objetivo principal é criar e motivar projetos inovadores que resolvam problemas e grandes desafios da sociedade, ou seja, fornecer soluções que não sejam pontuais ou assistencialistas, além de reunir estudantes interessados em desenvolver conhecimentos e atividades práticas focadas em um tema específico.

Dentre os temas de interesse levantados pelos discentes participantes, surgiu o interesse em desenvolver projetos relacionados à tecnologia de prototipagem por impressão 3D, cuja tecnologia estaria ao alcance para experimentações, tendo em vista a disponibilidade de equipamentos nos laboratórios dos cursos de Engenharia da Instituição. A partir deste interesse, surgiu o Projeto Protosonho, que consiste na produção de próteses em impressora 3D, inicialmente com o foco em doações, a partir dos recursos próprios da instituição e mesmo dos alunos. O projeto visa desenvolver habilidades técnicas e empreendedoras dos alunos do IBMEC - MG. E tem como foco oferecer melhor qualidade de vida para deficientes físicos de baixo poder aquisitivo.

O projeto se baseou em diversos projetos open source, disponibilizados na internet em plataformas como a Enable Prosthetics, que oferece a possibilidade de download de projetos básicos já adaptados para as principais deficiências de membros superiores, sejam ausências de dedos, mãos ou braços (Figura 1).

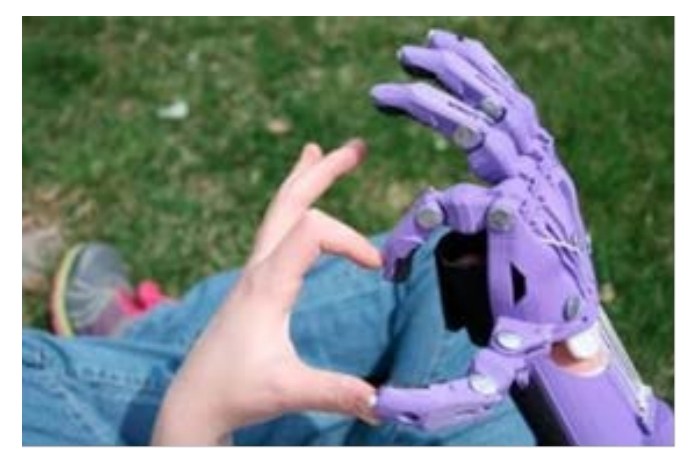

Figura 1 - Modelo de prótese de mão obtida a partir da impressão 3D de modelo disponibilizado na plataforma "Enable the Future". Fonte: disponível no site enablethefuture.org 
O uso dos projetos disponibilizados foi um ponto de partida para o grupo. 0 desenvolvimento de próteses ortopédicas antropomórficas exige a elaboração de modelos matemáticos paramétricos, baseados em conceitos de anatomia, fisiologia e cinesiologia. Estes modelos devem permitir a análise e a repetição de movimentos e de esforços executados, para que se possam aplicar os conceitos cinemáticos e dinâmicos dos dispositivos mecânicos a serem desenvolvidos, perfazendo uma interconexão com o sistema orgânico que o usuário dispõe, conforme o caso da aplicação. Deve ser analisado o seu grau de deficiência, para que o modelo seja alterado em função da sua realidade, delimitando a função da prótese em substituir somente as partes e movimentos do corpofaltantes.

A elaboração destes modelos constitui um grande desafio, pois, apesar do grande número de técnicas de modelagem matemática e de simulação hoje disponíveis, ainda não se tem conhecimento de sistemas que apresentem um nível de funcionamento que se aproxime em equivalência aos dos sistemas naturais. Este fato é um dos principais problemas que não permitem uma perfeita combinação entre o sistema orgânico existente e o artificial que se pretende inserir (BARROS, 2005).

Segundo Barros (Op. Cit.), as próteses de membros superiores podem ser classificadas de acordo com seu potencial funcional, seus componentes e suas fontes de energia. Dessa forma, classificam-se as próteses como não-funcionais ou passivas e funcionais ou ativas. As próteses não-funcionais são, em geral, semi-móveis ou totalmente imóveis e muitas vezes são utilizadas somente por razões estéticas, podendo estas serem usadas em todos os níveis de amputação. Já as próteses funcionais, esta autora as subdivide em:

, Próteses ativadas por movimentos do corpo - ativas ou mecânicas: a força do movimento de uma determinada parte do corpo se reflete na execução de movimentos da prótese. As próteses disponibilizadas nas plataformas online são dos tipos funcionais e ativadas pelos movimentos do corpo;

, Próteses energizadas por unidades externas: utilizam fontes de energia externa (energia extra-corpórea), como as baterias e, em geral, são controladas pelo movimento de estruturas naturais remanescentes ou através da atividade eletromiográfica fornecida por um grupo muscular escolhido;

, Próteses híbridas: junção das próteses ativa e mioelétrica (fonte interna e externa). Em amputações de membros superiores o controle mioelétrico pode ser combinado com um sistema de arreios que são cabos e cintas de suporte.

Para a mesma autora, idealmente uma prótese deve ser controlada sem o mínimo esforço do usuário, de forma similar ao controle subconsciente de um membro natural. Contudo, esse fato não acontece em virtude das limitações ainda existentes nas próteses até então desenvolvidas.

O processo da impressão 3D consiste basicamente na fabricação de uma peça a partir da deposição de um determinado material em camadas sobrepostas repetidas vezes até que se tenha o modelo completamente constituído, materializado, tal como o modelo virtual (matemático) obtido através de softwares CAD (computer aided design).

No campo do design esta tecnologia foi aplicada pela primeira vez com o objetivo de confeccionar modelos e protótipos, devido ao ganho de tempo e 
velocidade na construção de modelos funcionais em relação aos tradicionalmente feitos à mão. Hoje ela se encontra consolidada como ferramenta do processo de desenvolvimento de produtos (DIMITROV, SCHREVE e DE BEER, 2006).

O processo Fused Deposition Modeling (FDM) ou "Deposição de Material Fundido" é o processo atualmente mais acessível em termos de custos de equipamento e de matéria-prima, no qual um determinado material em estado plástico é seletivamente depositado em camadas, em uma plataforma através de um bico extrusor, conforme Figura 2. Para completar cada camada, este bico vai depositando o material em todo o contorno da seção e, depois de terminado, passa preencher o conteúdo do contorno, geralmente em movimentos de vai e vem. Depois que a primeira camada é terminada, o bico sobe alguns décimos de milímetro e inicia a fabricação da segunda camada, e assim vai fazendo sucessivamente até que a peça esteja completa.

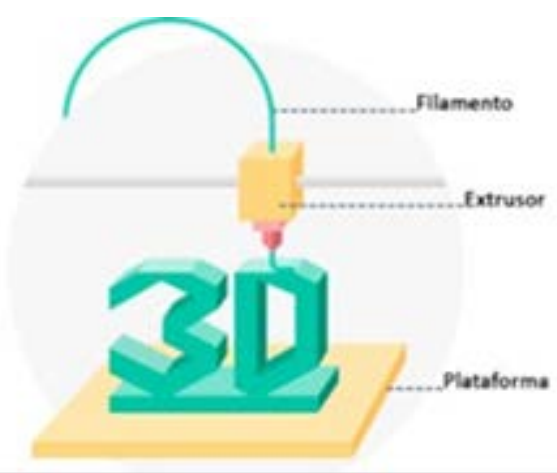

Figura 2 - Esquema ilustrativo da impressão 3D através do processo FDM Fonte: THRE3D, 2014

O processo de confecção de próteses ativadas por movimentos do corpo, através das técnicas tradicionais, envolve a seleção e fabricação de ferramentais específicos com formato antropomorfo, copiado da parte corporal do indivíduo específico que a receberá. Isso caracteriza um processo de fabricação no qual as partes de interface serão únicas, portanto com projeto e ferramentais dedicados, os quais serão utilizados uma única vez, para a fabricação daquela única peça que servirá de acoplamento da prótese ao corpo do indivíduo. Os materiais de fabricação são nobres, com eles busca-se a durabilidade, conforto e confiabilidade do sistema, a seleção desses materiais é baseada na capacidade de resistência mecânica e na leveza que possuem. São exemplos: compósitos de fibra de carbono, kevlar e ligas de titânio, cujo processamento e fabricação de peças em lotes pequenos, onde não há economia de escala, também tornam sua confecção muito dispendiosa. A impressão em 3D, através do processo FDM já descrito anteriormente, veio viabilizar a confecção destes dispositivos assistivos ao permitir a impressão de suas partes em pequenas quantidades e até mesmo em quantidade única. Além de ser um processo financeiramente acessível, tendo em vista a disponibilidade ampla de impressoras, em função da disseminação da tecnologia e da oferta de equipamentos de baixo custo, até mesmo através de projetos disponibilizados em plataformas online, no formato de projetos DIY ("Do It Yourself", ou "faça você mesmo sua própria impressora 3D"). Ou seja: substituir uma tecnologia principal por uma de baixo custo. 
A seleção deste processo entrou em consonância com os objetivos e diretrizes do empreendedorismo social pretendido, pois viabiliza a produção das próteses em função do baixo custo e da disponibilidade dos 17 FabLabs espalhados pelo país. Para a produção do nosso projeto, utilizamos o FabLab da Escola de Design da Universidade do Estado de Minas Gerais (UEMG), que proporcionou à equipe a possibilidade de uso de uma infraestrutura já instalada, com a disponibilidade de impressoras 3D, scanner 3D, máquinas de usinagem CNC e corte à laser, dentre outros equipamentos e softwares que viabilizaram a consecução dos resultados aqui descritos.

Além da infraestrutura, o desenvolvimento do projeto multidisciplinar contou com a participação de atores de diversas formações e aptidões, caracterizando enlace de diversas competências que se entrecruzam e se completam. Tendo em vista, que a equipe de desenvolvimento do projeto Protosonho, contou com a participação de alunos de Economia, Administração, além das Engenharias de Produção, Mecânica e Civil. Ademais, o contato com o FabLab da UEMG permitiu a interação entre duas disciplinsa que tem grande interface: o Design e a Engenharia. Esta peculiaridade determina uma relação de interface, que para muitos pode se apresentar dicotômica (Figura 3), mas que apresenta na prática uma série de equivalências e complementações, caracterizando a interdisciplinaridade (ANDRADE, 2004):

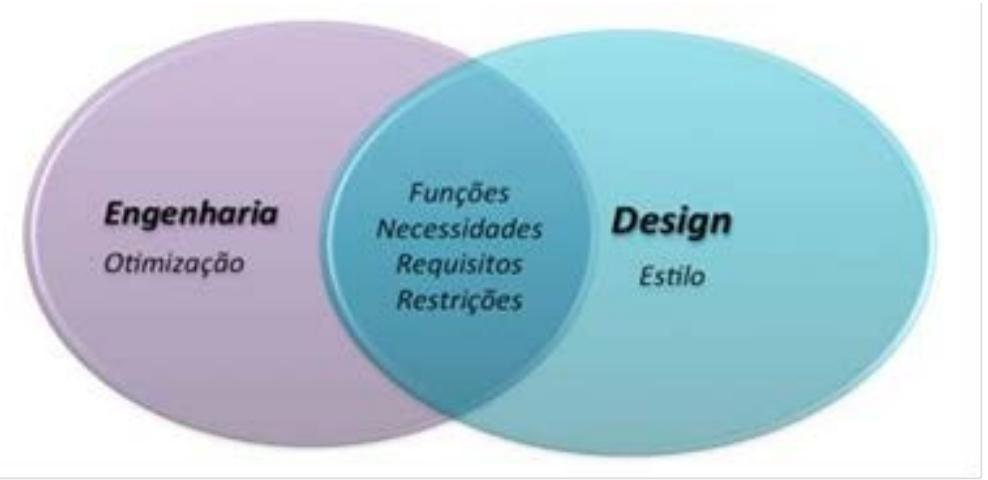

Figura 3 - Interação entre o design e a engenharia.

Fonte: Adaptado de Andrade, 2004

Os métodos empregados para o desenvolvimento do projeto multi e interdisciplinar seguiram as diretrizes do processo de design (BAXTER, 2000) combinados aos métodos de desenvolvimento de produtos da engenharia (CLARK \& WHEELWRIGHT, 1993) onde ferramentas criativas de desenvolvimento em grupo como brainstorming e brainwriting foram combinadas a processos de tomada de decisão e de otimização das propostas, típicos das Engenharias.

\section{PROPOSTA DE INTERVENÇÃO - A COLABORAÇÃO DO DESIGN}

O ponto de partida para a execução do projeto baseou-se do interesse já relatado pelos alunos, seguido pela disponibilidade e adequação da tecnologia de prototipagem rápida pelo processo FDM. Mas o grande catalisador que promoveu a saída da inércia e o início do projeto, enquanto etapa piloto, foi o desafio lançado pelo programa da Rede Globo de Televisão, intitulado "FabLab", em cuja estréia lançou o desafio do projeto de uma prótese de mão para uma criança de 7 anos de 
idade, com deficiência de nascença em uma de suas mãos, que possui apenas a palma e o polegar, com a ausência dos outros quatro dedos.

Neste contexto, a equipe interessada em desenvolver o projeto pontapé do Protosonho se reuniu e passou o desafio ao corpo discente a instituição, de maneira a promover o projeto e de adquirir adesão de interessados. Deu-se o início do projeto. A primeira etapa desenvolvida, foi o download do projeto original na plataforma Enable, adequado à situação do indivíduo a ser atendido, no caso, a criança de 7 anos. A prótese base, obtida na plataforma virtual, tem sua configuração básica determinada pela modelagem paramétrica em um único tamanho. E em configurações baseadas nas principais deficiências identificadas, relacionadas à sua maior incidência, como p.ex. falta da mão, falta dos dedos, etc. A plataforma disponibiliza uma tabela que indica fatores de escala de impressão, conforme a idade do usuário a ser contemplado pela prótese. Notamos, a partir da coleta de depoimentos no programa televisivo, que uma das maiores reclamações da criança, com relação às próteses impressas em 3D a partir do mesmo modelo de resolução, tratavam do desconforto na interface, ou seja, na área de contato com o corpo.

Tendo em mente esta observação e o fato de a criança ter o seu polegar intacto e ativo, a equipe se reuniu para discutir as possibilidades de intervenção, para a elaboração de uma proposta de desenvolvimento que se apresentasse como solução viável e eficiente.

Dentre as propostas e alternativas levantadas pela equipe, consideramos que a melhor solução para o desenvolvimento do projeto seria o cumprimento das etapas previstas abaixo:

, Escaneamento em 3D do membro deficiente, de forma a obter as medidas reais da superfície de interface corpo-prótese, para que o modelamento paramétrico proporcionasse uma prótese dedicada ao usuário. Tendo em vista as diretrizes e limitações do projeto, consideramos esta uma etapa viável, porque atualmente, é relativamente simples realizar o escaneamento de uma superfície ou corpo, inclusive através do uso de um celular do tipo smartphone;

Após serem obtidas as medidas corporais da zona de interface, a partir do escaneamento $3 \mathrm{D}$, os dados obtidos deveriam ser adequados às partes específicas da prótese a ser impressa em 3D, especificamente as que promoveriam o contato superficial com o membro deficiente do usuário. Os ajustes envolveriam ajustes de escala destes componentes e até mesmo a consideração de critérios como a contração do plástico, ao passar do estado pastoso para sólido, no processo FDM. Estes critérios passariam a ser diretrizes projetuais em intervenções e projetos da mesma natureza;

Os modelos obtidos a partir das plataformas online, tais como a Enable, teriam então que ser revistos, com o objetivo de adequação da modelagem de suas partes, com a retirada ou a adição de partes que estivessem de acordo com a realidade de cada usuário, que é única. No caso da criança a ser atendida, a ausência dos dedos, porém, com a presença do polegar, ativo. Nesta etapa, a contribuição dos profissionais de design foi fundamental, tendo em vista a desenvoltura destes na manipulação dos arquivos digitais de modelagens paramétricas. Especificamente em relação a este projeto, 
consideramos a retirada do polegar da prótese e a retirada de uma das conexões do pulso, transformando-a em uma conexão com rótula, permitindo as movimentações naturais da mão, em flexão, extensão, em desvio ulnar ou desvio radial (Figura 4). Para proporcionar o desvio ulnar e o desvio radial, impossíveis de serem desenvolvidos enquanto posturas ou movimentos na prótese original, foi selecionado um encaixe do tipo rótula, com o emprego de rolamentos do tipo rótula, de carga radial, conforme Figura 5;

, Optamos pelo emprego do polegar ativo enquanto acionador do sistema, tornando-o o responsável pela articulação dos outros dedos. A alternativa sugerida para proporcionar este movimento seria viabilizada no protótipo através de cordas ligadas ao dedo polegar, que ao ser fechado, tracionaria o conjunto, obrigando os dedos artificial da prótese a se fecharem, desenvolvendo assim o movimento de pega cilíndrica.

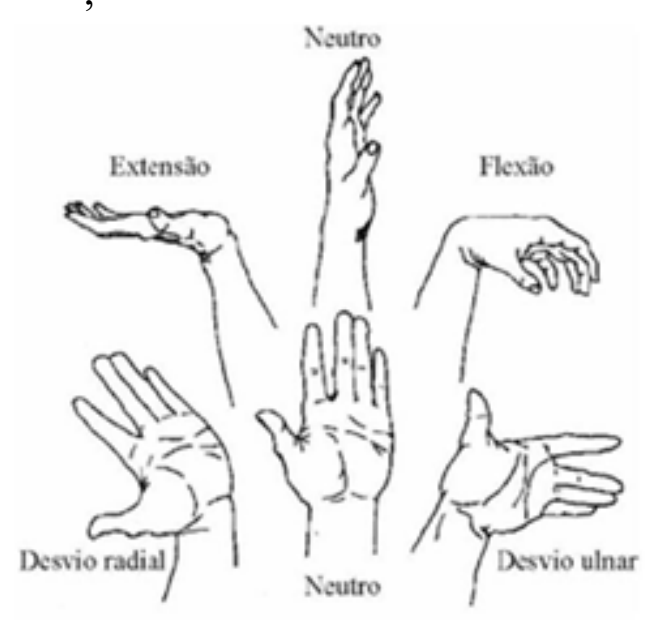

Figura 4 - Posturas naturais das mãos Fonte: lida, 2005.

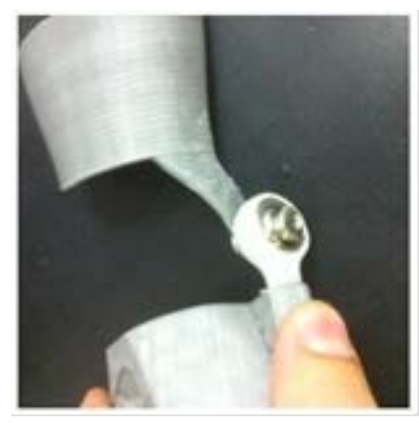

Figura 5 - Dispositivo tipo rótula selecionado para o projeto

Fonte: Elaborado pelos autores, com base na pesquisa realizada

O referido projeto ainda se encontrava em etapa de finalização, até o fechamento deste artigo, impossibilitando o registro dos testes do protótipo.

\section{RESULTADOS E DISCUSSÃO}

Mostramos a seguir as imagens do modelamento matemático (paramétrico) dos componentes da prótese a ser desenvolvida e enviada para avaliação do usuário (Figuras 6 e 7). 


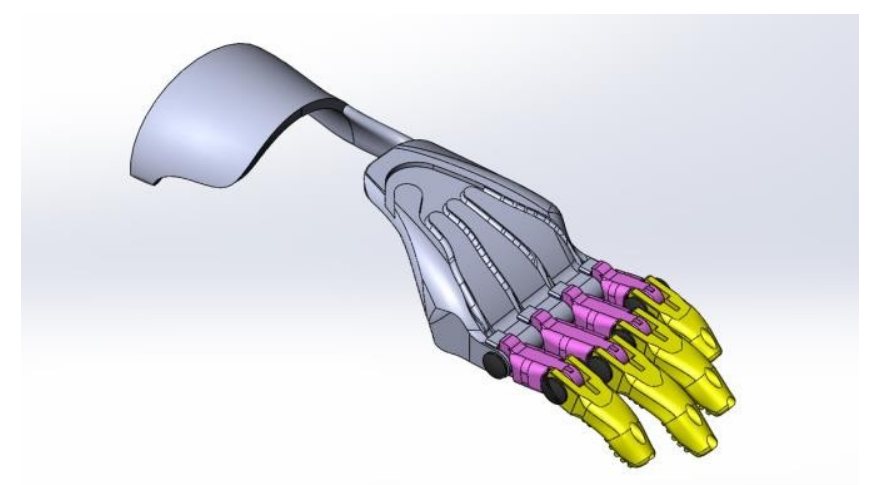

Figura 6 - Projeto do protótipo inicial - Plataforma CAD (Solidworks ${ }^{\circledR}$ )

Fonte: Elaborado pelos autores, com base na pesquisa realizada

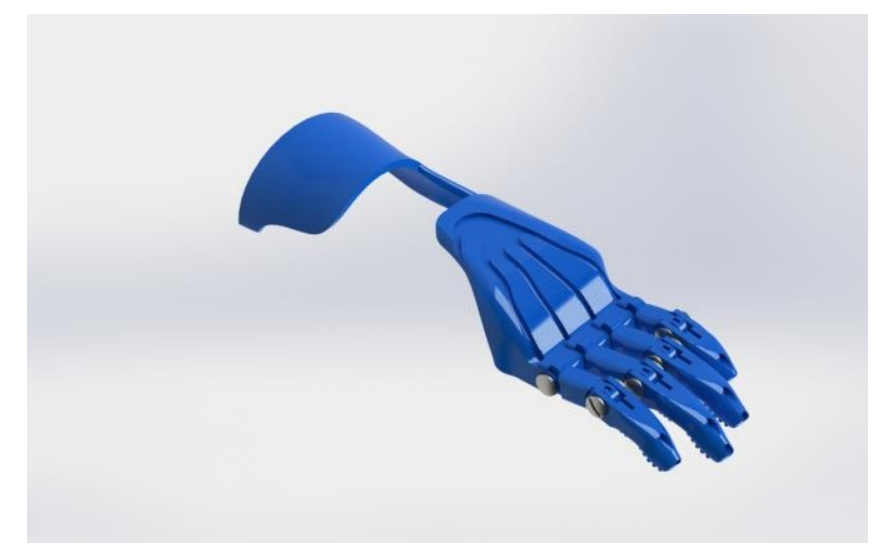

Figura 7 - Rendering do projeto do protótipo inicial - Plataforma CAD (Solidworks ${ }^{\circledR}$ ) Fonte: Elaborado pelos autores, com base na pesquisa realizada

Nota-se que o dedo polegar da prótese original foi suprimido da modelagem inicial, de forma a deixar livre a movimentação deste membro do usuário, que se apresenta ativo e útil. As costas da prótese comportam canaletas que guiarão as cordas de kevlar responsáveis pela movimentação dos dedos, as quais serão canalizadas ao dedo ativo, o polegar, e o membro será envolvido por um dedal, que ao ser fechado, acionará o movimento dos membros artificiais da prótese. Sugerimos que o indivíduo faça uso de uma luva de material que proporcione conforto, respirabilidade e liberdade de movimentos. Para tanto, pretendemos confeccionar esta luva em tecido de Neoprene GRT, usado em artefatos contendo fibras têxteis, que além de proporcionar a liberdade pretendida, é um material que se adéqua a qualquer tipo de costura, ou seja, conforma-se de acordo com a forma pretendida, e proporcionará o conforto necessário na interface pretendida. A espessura do tecido, também deverá ser descontada na área de contato prótesecorpo.

\section{CONCLUSÃO}

Os agentes econômicos e sociais tradicionais se utilizam de estruturas, ferramentas e modelos de negócio para a consecução dos seus objetivos em um ambiente que evidência um pseudo-equilíbrio existente. Os atores que atuam nesse cenário e as tecnologias de envolvimento ("engagement technologies") concorrem 
para o estabelecimento de um equilíbrio injusto e insatisfatório, no qual o poder aquisitivo fornece acesso às benesses da tecnologia ainda não disseminada, ou de alto custo de seleção. Para Martin \& Osberg (2015), uma forma de se promover uma mudança radical neste contexto, seria a promoção de um incremento tecnológico descomunal, através de uma quebra de paradigma que, ao mesmo tempo, deixe estes atores em seu lugar. Para estes autores, existem três formas de se alcançar esse feito: substituição, criação ou readaptação. Na realidade do nosso projeto essa quebra de paradigma se da através da substituição da tecnologia principal - no caso a fabricação de próteses individuais no sistema tradicional, com materiais de alta tecnologia e valor agregado, por uma de baixo custo e acessível, a impressão em 3D pelo processo FDM.

O objeto do projeto tem proporcionado à equipe uma experiência abrangente, que envolve os conceitos fundamentais do empreendedorismo social, além de vivenciar um processo completo de desenvolvimento de produto centrado no usuário. O trabalho em conjunto, através de uma equipe multidisciplinar, também enriqueceu o processo e tornou atrativo o contexto de atuação dos agentes, a partir das competências que atuaram se completando, seja na organização, seja na alocação de recursos, seja na execução, propriamente dita, do projeto.

Esperamos que, com a finalização do projeto aqui relatado, o programa se estabeleça, definitivamente. E que a experiência tenha servido de base para estabelecer os procedimentos fundamentais para novas inserções, além de abrir caminhos para promover a sustentabilidade econômica e financeira do projeto, de forma a fortalecer e promover seu crescimento.

\section{REFERÊNCIAS}

ANDRADE, L. F. (2004). A dicotomização do conhecimento como forma de separação das disciplinas de projeto de produto e design de produto. Anais do XXIV ENEGEP - Encontro Nacional de Engenharia de Produção.

BARROS, K. Metodologia para classificação de sinais EMG para controle de próteses com baixo esforço computacional. Uberlândia, MG, Brasil, 2005.

BAXTER, M. Projeto de produto: Guia Prático para o Desenvolvimento de Novos Produtos. 3a edição revista; tradução Itiro lida. São Paulo: Edgard Blücher. 260p. 2011.

BITENCOURT, C. A gestão de competências gerenciais - a contribuição da aprendizagem organizacional. Porto Alegre: Escola de Administração da UFRGS, 2001 (Tese, Doutorado em Administração).

BORCHARDT, M.; VACCARO, G.; AZEVEDO, D.; PONTE JUNIOR, J. Avaliação das competências necessárias ao engenheiro de produção: a visão das empresas da região de Porto Alegre. XXVII Encontro Nacional de Engenharia de Produção ENEGEP 2007. Foz do Iguaçu, 2007.

BORRACHA ATUAL. Neoprene: Características, Compostos e Aplicações. Disponível em:<http://www.borrachaatual.com.br/adm/materias/5afe6f6a6678938ef11afde6d b3aef 86.pdf $>$. Acessado em 04/05/2016. 
CLARK K. B. and WHEELWRIGHT S. C. Managing New Product and Process

Development. New York: The Free Press, 1993.

DAVID, D. Intraempreendedorismo social: perspectivas para o desenvolvimento social nas organizações. Tese (Doutorado) - Universidade Federal de Santa Catarina, Programa de Pós-Graduação em Engenharia de Produção, 204 f., Florianópolis, 2004.

DIMITROV, D.; SCHREVE, K.; DE BEER, N. Advances in three dimensional printing state of the art and future perspectives. Rapid Prototyping Journal, Stellenbosch, $v$. 12, n. 3, p. 12, 2006.

DRUKER, Peter F. Inovação e espírito empreendedor (entrepreneurship): prática e princípios. São Paulo: Pioneira, 1987.

IIDA, I. Ergonomia - Projeto e Produção. 2a Edição Revista e Ampliada, 2005, São Paulo, Editora Blucher, 630p.

MARTIN, R.; OSBERG, S. Dois fatores-chave para o empreendedorismo social sustentável. Harvard Business Review Brasil. Maio, 2015. Disponível em:<http://hbrbr.com.br/dois-fatores-chave-para-o-empreendedorismo-socialsustentavel/> Acessado em: 04/05/2016.

SILVA, H. Empreendedorismo: o caminho para o sucesso no século XXI. Disponível em:<http://www.daeln.ct.utfpr.edu.br/ denisedavid/aulas/empreendedorismo/E mpreen dedorismoXXI.doc>. 2003. Acessado em: 04/05/2016.

THRE3D - 3D Printing, Simplified., 2014. Disponível em:<https://thre3d.com>. Acessado em 04/05/2016.

VIEIRA, R.; GAUTHIER, F. Introdução ao empreendedorismo social. Anais. II Encontro Nacional de Empreendedorismo. Florianópolis, 2000. 